\title{
ПРОБЛЕМНЫЕ АСПЕКТЫ ВЗАИМОДЕЙСТВИЯ АДВОКАТОВ И УГОЛОВНО-ИСПОЛНИТЕЛЬНОЙ СИСТЕМЫ
}

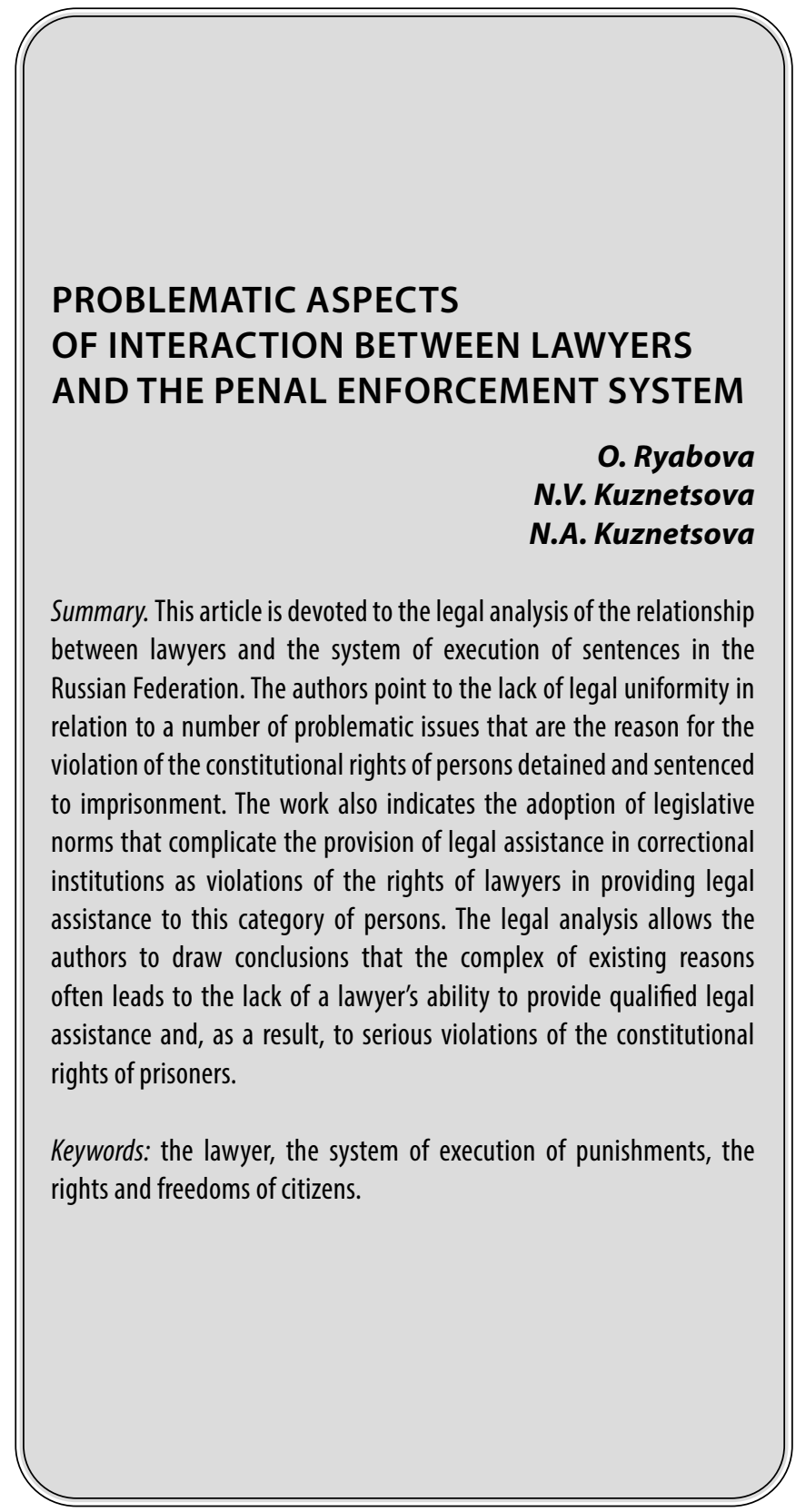

оссийская модель адвокатуры предполагает монополию адвокатов на представительство интересов лиц, совершивших уголовно-наказуемые деяния. Учитывая это, адвокатам достаточно часто приходится оказывать юридическую помощь своим подзащитным, находящимся под стражей в ожидании окончания следствия и суда, либо уже отбывающим наказание.
Рябова Ольга Алексеевна

Преподаватель, ФКОУ ВО «Владимирский юридический институт ФСИН России» frau.lelya2012@yandex.ru Кузнецова Наталья Владимировна Старший преподаватель, ФКОУ ВО «Владимирский юридический институт ФСИН России» kuznezova-1963@mail.ru Кузнецова Наталья Александровна Старший преподаватель, ФКОУ ВО «Владимирский юридический институт ФСИН России» kuz1503@yandex.ru

Аннотация. Настоящая статья посвящена правовому анализу взаимоотношений адвокатов и системы исполнения наказаний в Российской Федерации. Авторы указывают на отсутствие правового единообразия в отношении ряда проблемных моментов, которые являются причиной нарушения конституционных прав лиц, заключенных под стражу и осужденных к лишению свободы. Также в работе указываются в качестве нарушений прав адвокатов при оказании правовой помощи указанной категории лиц принятие законодательных норм, которые осложняют оказание юридической помощи в исправительных учреждениях. Правовой анализ позволяет авторам сделать выводы о том, что комплекс существующих причин нередко приводит к отсутствию у адвоката возможности оказания квалифицированной юридической помощи и, как следствие, к серьезным нарушениям конституционных прав заключенных. Ключевые слова: адвокат, система исполнения наказаний, права и свободы граждан.

Вопросы, связанные с взаимоотношением адвокатов и представителей пенетенциарной системы, достаточно часто поднимаются внутри адвокатского сообщества, а также на уровне межотраслевых встреч.

Проблемные моменты, возникающие в большинстве случаев у адвокатов при посещении своих подопечных в местах содержания под стражей и исправительных уч- 
реждениях проистекают из-за законодательной неурегулированности таких взаимоотношений, правового негативизма сотрудников уголовно-исполнительной системы и общего отношения государства в лице его властных органов к адвокатуре и профессиональной юридической помощи.

Основным законодательным актом, который регулирует профессиональную деятельность адвокатов, является Федеральный Закон от 31.05.2002 «Об адвокатской деятельности и адвокатуре в Российской Федерации». Осуществляя свою профессиональную деятельность, адвокаты реализуют нормы о защите прав и свобод российских граждан, предусмотренные Конституцией Российской Федерации.[1] И тот факт, что лицо совершило преступление и находится под надзором системы исполнения наказаний, не лишает его конституционных прав. Известны случаи, когда сотрудниками учреждений службы исполнения наказаний нарушались права и свободы отбывающих наказание лиц. В таких ситуациях заключенному необходима помощь адвоката. Однако, в силу слишком радикальной трактовки отраслевого законодательства, сотрудниками уголовно-исполнительной системы в предоставлении такой помощи отказывают путем недопуска адвоката к своему подзащитному по различным основаниям. Следует иметь в виду, что причинами таких отказов могут быть как внезапные карантинные меры, отсутствие выводящего сотрудника, временное ограничение для встреч (всего несколько часов в течение рабочего дня) и некоторые другие, что является противозаконным, так и ссылки на уголовно-исполнительный кодекс Российской Федерации и на отраслевое законодательство в целом, а также на внутренние инструкции.

Так, ст. 118 УИК РФ особо оговаривает, что, лицо, находящееся в штрафном изоляторе, не имеет право на свидания и встречи.[3] Сотрудники уголовно-исполнительной системы трактуют эту норму буквально и во встречах отказывают, в том числе и адвокатам. Однако данная норма не распространяется на лиц, имеющих статус адвоката и желающих встретиться с заключенным в рамках оказания правовой помощи, учитывая волеизъявление об оказании такой помощи, исходящее от лица, содержащегося под стражей. Право адвоката на беспрепятственную встречу с доверителем, находящимся под стражей, без ограничения числа свиданий и их продолжительности, закреплено Законом об адвокатской деятельности и адвокатуре.[2]

Налицо правовая коллизия, основанная на отсутствии уточнений как в уголовно-исполнительном законодательстве, так и в законодательстве об адвокатуре. Верховным судом Российской Федерации были внесены разъяснения в отношении указанной проблемы, однако правоприменительная практика в Российской Федера- ции не считает источником права судебный прецедент и указанные разъяснения являются таковыми лишь для судейского корпуса. Безусловно, в случае подачи жалобы в суд адвокатом на действия сотрудников пенетенциарной системы при подобных обстоятельствах, велика вероятность того, что такая жалоба будет удовлетворена, однако время будет упущено и нуждающееся в юридической помощи лицо ее не получит своевременно. Следовательно, конституционные права лица, содержащегося под стражей, будут нарушены.

Необходимо понимать, что право, осужденных к лишению свободы лиц и лиц, находящихся под стражей закреплено не только Конституцией РФ, но и Уголовно-процессуальным кодексом РФ[4] и Уголовно-исполнительным кодексом РФ[3], а также отражено в локальных отраслевых актах. Причем, указанное выше право касается всех перечисленных лиц, в том числе подвергнутых дисциплинарному взысканию (например, нахождение в изоляторе). Здесь же важно отметить исключительную значимость оказания юридической помощи указанной категории граждан, так как ограниченный доступ к правовой информации не позволяет им в полной мере реализовывать свои права.

Представляется необходимым определение четких законодательных положений по данному вопросу и закрепление их, единообразно и в уголовно-исполнительном законодательстве, и в законодательстве об адвокатуре. У правоприменителей не должно остаться вопросов о трактовке норм права. Должно быть понятно, что адвокат имеет право на свидание со своим подопечным без каких-либо ограничений. Также хотелось бы отметить, что указанное в законодательстве ограничение свиданий с защитниками 4 часами [3] не соответствует Конституции РФ и должно быть подвергнуто законодательной корректировке. Свидание с адвокатом лиц, отбывающих наказание или содержащихся под стражей не должно ограничиваться во времени, хотя разумные пределы с точки зрения графика работы учреждения, конечно, должны быть.

Также в рамках описанных выше ограничений считаем необходимым отдельно отметить ограничения на допуск адвокатов к своим подопечным, находящимся в местах заключения, во время объявленной пандемии коронавирусной инфекции. С момента наступления известных событий весной 2020 года в следственных изоляторах и местах отбывания наказаний были введены ограничения на свидания, в том числе с адвокатами, вплоть до полного отказа в них на неопределенное время. Это, на наш взгляд, яркий пример нарушения прав лиц, содержащихся под стражей или осужденных к лишению свободы. Необходимо отметить, что Конституция РФ предполагает отдельные ограничения прав и свобод граждан с указанием пределов их действия.[1] Однако 
такие ограничения могут быть обусловлены только условиями чрезвычайного положения. Режим чрезвычайного положения в Российской Федерации не вводился, следовательно, законных оснований к ограничению свиданий адвокатов с подзащитными, не усматривается. Таким образом, мы можем констатировать нарушения норм Конституции РФ, а следовательно и прав заключенных, которые не получили своевременную юридическую помощь по указанным причинам, искуственно созданным представителями пенетенциарной системы, когда внутренние правила и распоряжения противоречат основному Закону страны.

Еще одним примером ограничения прав адвокатов при оказании юридической помощи лицам, находящимся под стражей или отбывающим наказание, является введение запрета для адвокатов на пронос на территорию исправительных учреждений технических средств связи, устройств, которые позволяют осуществлять аудио-, видеосъемку. К числу разрешенных технических средств разрешена копировально-множительная техника и фотоаппаратура, однако ее использование разрешено только в отсутствии заключенных.[3] При этом принятие указанных поправок стало возможным не смотря на то, что Верховный суд в своих судебных актах неоднократно занимал противоположную позицию по данному вопросу, однако мнение суда, как и мнение адвокатского сообщества услышаны законодателями не были.

Запрещенные на настоящий момент указанными поправками к проносу средства связи не должны рассматриваться государством как нечто противозаконное и в контексте того, что адвокат обязательно попробует дать подзащитному возможность воспользоваться такими средствами. Указанные средства представляют для адвокатов помощь в исполнении ими своих профессиональных обязанностей, так как внутри таких средств (современные телефоны, планшетные компьютеры и т.д.) содержится необходимая информация. Планируя встречу с подзащитным в учреждениях пенетенциарной системы, адвокат не всегда может предусмотреть, какой документ или нормативный акт ему понадобиться, а благодаря запрещенной новыми поправками технике такие документы и законы всегда доступны адвокату.

Складывается впечатление, что государство рассматривает адвоката как некий чуждый элемент в системе взаимоотношений государства (пенетенциарной системы) и лица, заключенного под стражу или отбывающего наказание в виде лишения свободы. Нет необходимости говорить о том, что взаимоотношения представителей следственных органов с сотрудниками уголовно-исполнительной системы находятся на более «дружественном» уровне. Хотя следует заметить, что законодательное регулирование осуществляется и ограничивается рамками одних и тех же законодательных актов. Безусловно, процессуальное неравноправие между адвокатами и представителями следствия с серьезным перевесом последних сказывается на взаимоотношениях адвокатов с представителями уголовно-исполнительной системы. Тем не менее, процессуальное равноправие сторон является одним из законодательных принципов. А учитывая монополию адвокатов по защите лиц совершивших уголовно-наказуемые деяния или подозреваемых в совершении таких деяний, необходимо понимать, что адвокат является единственной процессуальной фигурой, осуществляющей защиту прав заключенного.

Приходится констатировать, что в свете затронутой проблемы, такой обязательный признак цивилизованного уголовного и уголовно-исполнительного процесса как состязательность сторон, декларируемый государством как достигнутая данность, на самом деле далек от реального воплощения и нуждается в серьезном внимании законодателя, ставящего перед собой задачу построения правового государства,

Учитывая вышеперечисленное, можно сделать вывод о том, что государство не заинтересовано в стабилизации по данному вопросу и пока оно не изменит свое отношение к указанной проблеме, права адвокатов и указанной категории лиц будут нарушаться и в дальнейшем.

В этом смысле весьма полезным будет являться пример Германии, где фундаментально закреплено правовое положение адвоката, которое заключается в том, что адвокат является независимым органом осуществления правосудия. Это означает, что адвокатура в Германии уполномочена осуществлять задачи правового государства наравне с судебными учреждениями, прокуратурой, органами полиции и исправительными учреждениями. [5] Адвокатура рассматривается как равный игрок на правовом поле, что заставляет уважать и считаться с ним, чего, к сожалению, нельзя сказать о положении адвокатуры в России. Полагаем, что если бы российское государство рассматривало адвокатуру в указанном контексте, то взаимоотношения адвокатуры и уголовно-исполнительной системы находились бы на ином качественном уровне, приносящем только пользу.

Резюмируя вышесказанное, полагаем, что проблемы сложных взаимоотношений адвокатуры и уголовно-исполнительной системы, в первую очередь, отражается на соблюдении законности в отношении указанной в статье категории граждан, находящихся в изоляции и порой остро нуждающихся в правовой помощи, защите их прав, в том числе конституционных, и законных интересов. 
ЛИТЕРАТУРА

1. Конституция Российской Федерации (принята всенародным голосованием 12 декабря 1993 года) // Российская газета. № 237 25.12.1993 г.

2. Федеральный Закон от 31.05.2002 № 63 — Ф3 «06 адвокатской деятельности и адвокатуре в Российской Федерации» (в ред. от 29.07.2017) // Российская газета. № 100 05.06.2002.

3. Уголовно-исполнительный кодекс Российской Федерации от 08 января 1997 г. № 1 — Ф3 // Российская газета. № 9-10 16.01.1997 г.

4. Уголовно-процессуальный кодекс Российской Федерации от 18 декабря 2001 г. № 174 — Ф3 // Российская газета № 24922.12 .2001 г.

5. Карташев М.А. Реформа адвокатской деятельности в Германии.—-Адвокатская газета, июль.— 2021

( Рябова Ольга Алексеевна ( frau.lelya2012@yandex.ru),

Кузнецова Наталья Владимировна ( kuznezova-1963@mail.ru ), Кузнецова Наталья Александровна ( kuz1503@yandex.ru ).

Журнал «Современная наука: актуальные проблемы теории и практики»

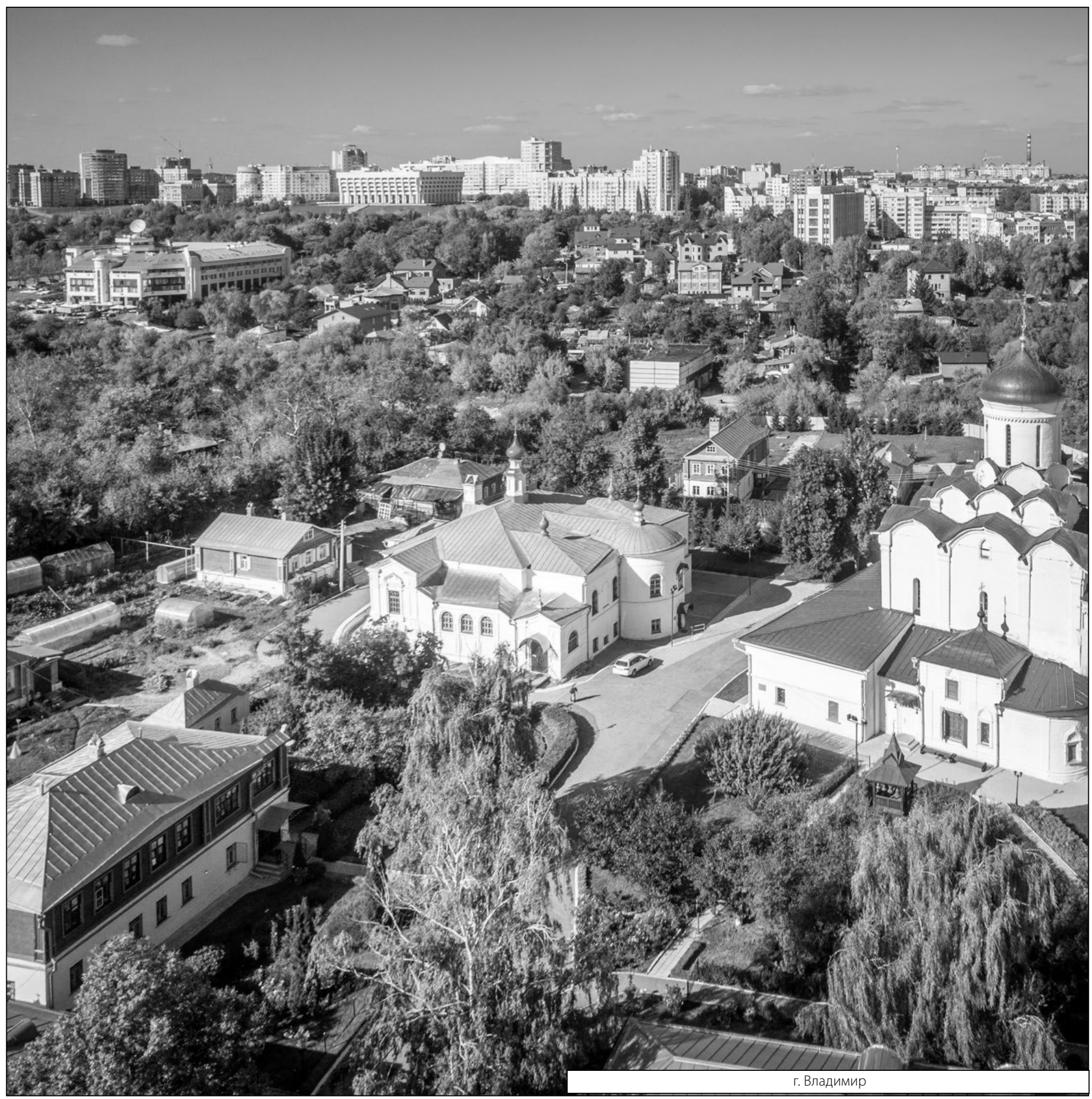

